\title{
Russia-Germany: \\ Perceptions and Motives
}

\section{How to Mend Bilateral Relations}

\section{Ivan N. Timofeev}

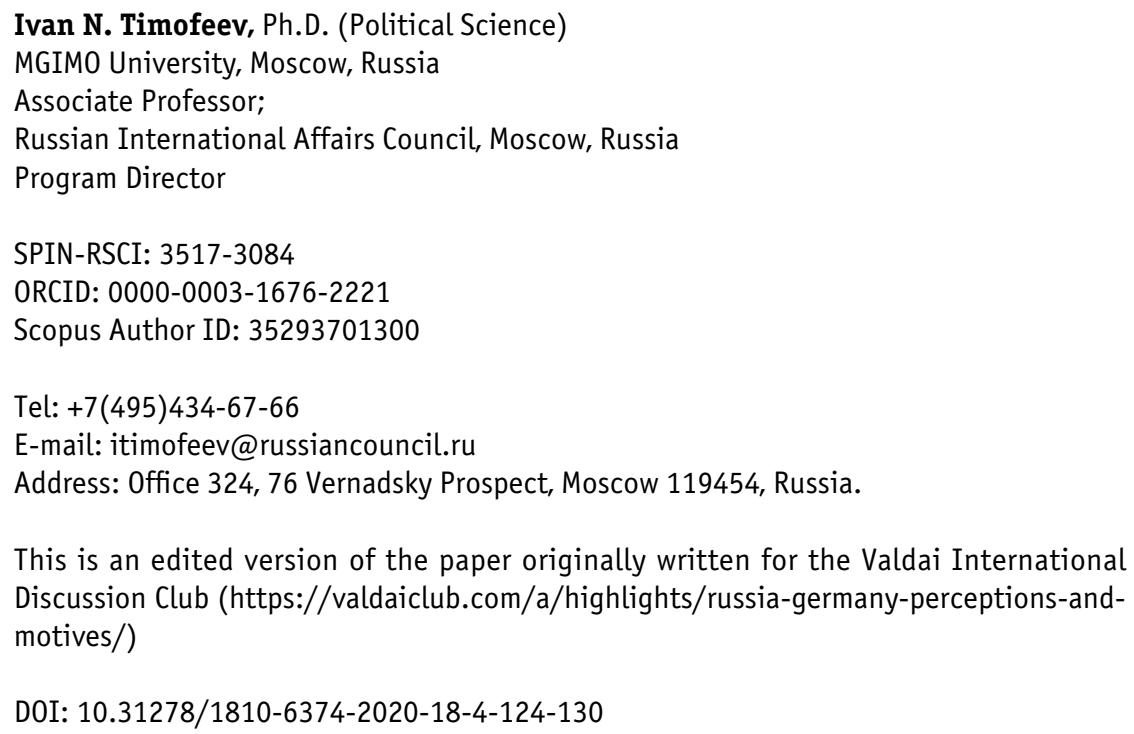

This is an edited version of the paper originally written for the Valdai International Discussion Club (https://valdaiclub.com/a/highlights/russia-germany-perceptions-andmotives/)

DOI: $10.31278 / 1810-6374-2020-18-4-124-130$

The West has long been trying to decipher the "genome" of the Kremlin's policy. Many of these attempts are interesting and original, but there is at least one systemic problem in them-an attempt to find a universal model for explaining Russia's policy that would make it possible to understand it in its entirety, that is, to generalize separate events within one scheme.

The Carnegie Moscow Center's portal has published Sabina Fisher's article titled "From a Gas Pipeline to Navalny. What the 
Kremlin Does Not Understand about Germany." It attempts to provide an insight into the aggravation of relations between Russia and Germany in the context of the Alexei Navalny case, and why Moscow errs in perceiving Germany's Russia policy.

The underlying idea of the article is that the Navalny incident is just one of the episodes in the long story of Germany's long-term disillusionment with Russia. It began after the 2011 Duma elections and swiftly followed Vladimir Putin's return as president in 2012. The events in Ukraine, the war in Syria, Russia's alleged interference in U.S. presidential election, cyber-attacks, the Skripal case, and the current situation around Navalny caused more and more frustration in Berlin. At the same time, Germany is mistakenly perceived in Russia as a "special partner" that better understands Moscow's motives and acts as a mediator in solving difficult situations. In fact, Berlin is actively promoting EU interests in the post-Soviet space, continuing its policy of active integration of its Eastern European neighbors into the EU space.

Russia is increasingly perceived in Germany as a threat. The Kremlin either does not know it, or does not understand it, or is generally indifferent to all this.

In fact, the issue of perception and motives is one of the key elements in international relations. There have been many cases in history when errors in the perception of the motives and actions of the opposite side led to severe crises. From the point of view of human nature, such mistakes are inevitable. We have different experiences, cultures, and views. The differences are multiplied in large human communities, such as states. Perceptual patterns can be extremely inertial. In politics, they are also often distorted and subjective.

It would seem that scientists could unravel the tangle of motives. But they are human beings too. Max Weber's ideal was a pursuit of social sciences unencumbered by cultural values. However, this ideal is hardly attainable. Karl Popper warned about the impossibility of objective knowledge. The alternative is to leave it 
open to criticism and constant reverification: "The objectivity of science is not a matter for the individual scientist, but rather the social result of mutual criticism, of the friendly-hostile division of labor among scientists, of their co-operation and also of their competition." Employing a critical method in assessing politics is especially important. Politics is woven from ideology. It is dogmatic and can hardly be any different. Critical method and discussion are almost all that allow us to look at perceptions and motives from different angles. A scientist brings empathy into politics. He takes the position of each of the parties, trying to understand their motives and driving forces.

For a long time, we have been discussing relations between Russia and the EU within the framework of the EUREN joint expert group. In the spirit of such a critical discussion I will try to offer my quick take on perceptions and motives, as well as their reflection on our politics.

The West has long been trying to decipher the "genome" of the Kremlin's policy. Many of these attempts are interesting and original, but there is at least one systemic problem in them-an attempt to find a universal model for explaining Russia's policy that would make it possible to understand it in its entirety, that is, to generalize separate events within one scheme.

Such style of thinking is generally characteristic of the Enlightenment model of cognition-finding a rational scheme or pattern to explain a lot of events. We have been absorbing the ideals of the Enlightenment for several centuries, but they are not free from flaws. The main problem is that fundamentally different events are often linked into a single canvas. This mode of perception and analysis looks quite logical and harmonious, but in reality similar events can be caused by completely different reasons. For example, many are tempted to link the 2008 five-day war in Georgia with the events in Ukraine in 2014 within a single rationale, a theoretically generalized notion of "Moscow's aggressive 
policy." Such an approach provides a clear picture for perception, a certain intellectual comfort for scientists-here is a ready key to understanding what is going on. In practice, however, each of these episodes had its own reasons and motives, so this mode of thinking can hardly explain Russia's behavior on a case-by-case basis as many important details remain in the shadow. Another example is the notion of 'the Putin regime' often found in scientific works and political texts. This is a case where different events are arbitrarily linked through a regime or personality. It follows that certain individual figures or institutions are omnipotent. No doubt, leaders and institutions do matter, but should scientists place them in the center of their analysis? This is a big question.

Ironically, Russia's perception of the West follows similar patterns. We also build our models of perception and, using the same logic, try to rationalize them, combining events that are poorly related to each other. "Color revolutions" are seen as part of a single insidious plan. Publications that are critical of Russia are seen to signify a common front in the information war. Washington's involvement in Yugoslavia, Afghanistan, Iraq, Libya, and Syria are seen as a manifestation of U.S. hegemony. Migrants, LGBT minorities, populism and protests are all seen as signs of the imminent decline of the West.

Both Russia and the West continue to rely upon clichéd models of thinking when looking at one another.

Obviously, we find it difficult to live without a model of perception. This is how our thinking works. And our capacity for rationalization creates an illusion that a certain model is correct. Assured of its veracity, we earnestly spread our convictions, and this reflection of reality turns into preaching. We ourselves should treat the products of our thinking with a healthy portion of skepticism and self-criticism.

What exactly does this mean if we seek to understand the motives behind the policies of Russia and Germany? 
In "decoding" Russian policies it is important to take into account the character of Russia as a player in the international arena. It is a great power, and its security interests play an essential role in determining the motives that underlie its behavior. The feeling of vulnerability and defensiveness are important driving factors in Russia's policies. In its own way, they also lead to a distorted view of reality, but many of Russia's actions are typical of the behavior of large and small powers pursuing their own interests. The "blame game" is usually unproductive in diplomacy, but from the moral point of view, Russia's operation in Syria is hardly better or worse than the U.S. operation there. The poisoning of the Skripals was just as disgusting (no matter who committed it or why), as the dismemberment of journalist Jamal Khashoggi. From the standpoint of morality, the murder of "Tornike" Khangoshvili was no better or worse than the attack on General Qasem Soleimani. The alleged Russian attack on the Bundestag servers and the scandal involving the U.S. wiretapping of the German chancellor should be regarded as similar offenses. This list is long, and it is unpleasant. Some of the worst foreign policy decisions seem to come from the same bag of tricks, regardless of their instigator.

Does it mean that such events should be ignored? No. Morality requires condemnation of any such action, regardless of its origin. And real policy requires concrete containment measures. The problem is that in politics both condemnation and deterrence are selective. We condemn one thing but turn a blind eye to other ones. We restrain some but avoid contacting others. Russia has been and will be an inconvenient partner for many. For Russia itself, some allies will be as inconvenient. The question is: How exactly can such "inconveniences" be managed? I think there is no general rule here. Each challenging episode will require its own separately tailored, ad hoc approach.

The art of diplomacy itself is about "managing inconveniences."

As for Russia’s perception of Germany, it is ridden with difficulties as well. Apparently, there is no single and holistic perception of Ger- 

many; it fluctuates and is beset by a wide range of stereotypes. Some underestimate Germany (calling it "Washington's vassal”), while others overestimate it ("the European bulldozer"). However, the opinion that Germany is a special partner for Russia really seems fairly common. There are many reasons for this. They include the volume of economic ties and the record of past relations, which could really be considered exclusive. In Russia, Germany is apparently perceived as less aggressive than the United States, and as more pragmatic and less Russophobic in comparison with the former Eastern European allies and Soviet republics, while being geographically and economically closer than the rest of Western Europe. Of course, this does not mean that Germany would stand apart from the common European or transatlantic policy on key issues. Therefore, I am skeptical about the widespread thesis that Germany's "special approach" to Russia ends with the Navalny case. The change in the Germans' attitude towards Russia is a long-term trend, and there is no doubt that it is negative. And, of course, Russians are neither ignorant of this trend nor indifferent to it. The question is: What exactly should Russia do to correct it and does Moscow have sufficient motivation to do so? If Berlin demands that Moscow "confess," promise "not to do it anymore" and give up a number of specific positions, then it should not expect much. Surrendering positions for the sake of a good relationship is definitely not among Moscow's plans.

On the other hand, it would be a mistake to let the situation take its course and ignore the rapidly deteriorating relations with Germany. The problem exists, and it requires serious attention from Russia. Germany and Russia have a large baggage of lucrative projects which both nations stand to gain from, as well as many common interests. Political crises and controversies on a number of issues will hardly set aside the need to build trust on specific issues without arrogance and sarcasm on either side. 